\title{
NECROLÓGICO
}

Arício Xavier Linhares 1

\section{Adão José Cardoso}

(1951-1997)

O Professor Dr. Adão José Cardoso nasceu em 13 de janeiro de 1951 em Campinas, São Paulo. Graduou-se como Bacharel em Ciências Biológicas pela Universidade de Campinas (UNICAMP) em 1975. Concluiu o Mestrado em Ecologia em 1981 e o Doutorado em 1985, ambos pela UNICAMP. Começou sua carreira em 1974 como professor de Ciências Biológicas no Colégio Pio XII. Em 1978 passou a coordenar a área de Ciências Biológicas da Pontifícia Universidade Católica de Campinas, cargo que ocupou até 1987, quando assumiu o cargo de Professor Assistente Doutor no Departamento de Zoologia, Instituto de Biologia da UNICAMP. Em 1995, prestou concurso público para Professor Livre Docente, na área de Zoologia de Vertebrados.

O Professor Adão sempre se destacou como um interessado no ensino, tanto de graduação como de primeiro e segundo graus. Foi Coordenador de Ensino de Graduação do Instituto de Biologia da UNICAMP por duas vezes, e esteve envolvido no desenvolvimento dos programas "Biologia no Parque" e "Museu Dinâmico de Ciências", em colaboração com a Prefeitura Municipal de Campinas. Foi também um grande incentivador e colaborador do Projeto Inajá, para educação de indígenas.

$\mathrm{Na}$ área científica, publicou 39 artigos e um livro, além de ter participado de 32 congressos nacionais e internacionais. Orientou doze estudantes de mestrado e três de doutorado. Foi também o criador e o responsável pelo Laboratório de Biologia, Ecologia e Bioacústica de Anfíbios do Departamento de Zoologia da UNICAMP, que possui um grande acervo de diapositivos, literatura e gravações sonoras de anfíbios neotropicais.

O passamento do Professor Adão é uma perda irreparável para a UNICAMP e para a comunidade de estudiosos da biologia e ecologia de anfíbios.

1) Departamento de Parasitologia, Instituto de Biologia, Universidade de Campinas. Caixa Postal 6109, 13083-970 Campinas, São Paulo, Brasil. 